\title{
Environmental and individual predictors of 25 -hydroxyvitamin $D$ concentrations in Denmark measured from neonatal dried blood spots: the D-tect study
}

\author{
Amélie Keller ${ }^{1 *}$, Peder Frederiksen ${ }^{1}$, Mina N. Händel ${ }^{1}$, Ramune Jacobsen ${ }^{1,2}$, John J. McGrath ${ }^{3,4}$, \\ Arieh S. Cohen ${ }^{5}$ and Berit L. Heitmann ${ }^{1,6,7}$ \\ ${ }^{1}$ Research Unit for Dietary Studies, The Parker Institute, The Capital Region, Bispebjerg and Frederiksberg University Hospitals, \\ 2000 Frederiksberg, Denmark \\ ${ }^{2}$ Research Unit for Chronic Conditions, Department of Clinical Epidemiology, Capital Region, Bispebjerg and Frederiksberg \\ University Hospitals, 2000 Frederiksberg, Denmark \\ ${ }^{3}$ Queensland Centre for Mental Health Research, Queensland Brain Institute, University of Queensland, St. Lucia, QLD \\ 4076, Australia \\ ${ }^{4}$ National Centre for Register-based Research, Aarbus BSS, Aarbus University, 821 Aarbus, Denmark \\ ${ }^{5}$ Staten Serum Institute, Clinical Mass Spectrometry, 2300 Copenhagen, Denmark \\ ${ }^{6}$ The Boden Institute of Obesity, Nutrition, Exercise E Eating Disorders, University of Sydney, Camperdown, NSW 2006, \\ Australia \\ ${ }^{7}$ The Department of Public Health, Section for General Practice, 1014 University of Copenhagen, Denmark
}

(Submitted 3 August 2018 - Final revision received 6 November 2018 - Accepted 27 November 2018 - First published online 30 January 2019)

\section{Abstract}

Environmental factors such as sunshine hours, temperature and UV radiation (UVR) are known to influence seasonal fluctuations in vitamin D concentrations. However, currently there is poor understanding regarding the environmental factors or individual characteristics that best predict neonatal 25-hydroxyvitamin D (25(OH)D) concentrations. The aims of this study were to (1) identify environmental and individual determinants of $25(\mathrm{OH}) \mathrm{D}$ concentrations in newborns and (2) investigate whether environmental factors and individual characteristics could be used as proxy measures for neonatal $25(\mathrm{OH}) \mathrm{D}$ concentrations. 25 -Hydroxyvitamin $\mathrm{D}_{3}\left(25(\mathrm{OH}) \mathrm{D}_{3}\right)$ was measured from neonatal dried blood spots (DBS) of 1182 individuals born between 1993 and 2002. Monthly aggregated data on daily number of sunshine hours, temperature and UVR, available from 1993, were retrieved from the Danish Meteorological Institute. The individual predictors were obtained from the Danish National Birth register, and Statistics Denmark. The optimal model to predict $25(\mathrm{OH}) \mathrm{D}_{3}$ concentrations from neonatal DBS was the one including the following variables: UVR, temperature, maternal education, maternal smoking during pregnancy, gestational age at birth and parity. This model explained $30 \%$ of the variation of $25(\mathrm{OH}) \mathrm{D}_{3}$ in the neonatal DBS. Ambient UVR in the month before the birth month was the best single-item predictor of neonatal $25(\mathrm{OH}) \mathrm{D}_{3}$, accounting for $24 \%$ of its variance. Although this prediction model cannot substitute for actual blood measurements, it might prove useful in cohort studies ranking individuals in groups according to $25(\mathrm{OH}) \mathrm{D}_{3}$ status.

Key words: Vitamin D: UV radiation: Dried blood spots: Neonates

The most well-known source of vitamin $\mathrm{D}$ is through skin synthesis induced by sun exposure. Studies from Northern Europe have highlighted a marked seasonal fluctuation in serum 25-hydroxyvitamin D (25(OH)D) concentrations among adults and newborns, with values being lowest in late winter and spring, because of less UV and skin-mediated vitamin D synthesis during these seasons ${ }^{(1)}$.

During gestation, the vitamin D stores of the fetus depend entirely on those of its mother ${ }^{(2)}$, and newborns' 25(OH)D concentrations are correlated with their mothers, ${ }^{\text {(3) }}$. Vitamin D insufficiency $(25(\mathrm{OH}) \mathrm{D}<50 \mathrm{nmol} / \mathrm{l})$ and deficiency $(25(\mathrm{OH}) \mathrm{D}$
$<25 \mathrm{nmol} / \mathrm{l}$ ) are common among otherwise healthy pregnant women, especially in high-latitude countries such as Denmark $\left(56^{\circ}\right.$ North) where UV radiation (UVR) from the sun (and thus vitamin D synthesis) is insufficient to produce vitamin D from October to $\operatorname{March}^{(4-7)}$. It has been estimated that $16-31 \%$ of Danish women suffer from vitamin D insufficiency in early pregnancy, of which $3 \cdot 5-6 \cdot 3 \%$ are vitamin D deficient ${ }^{(3,8-10)}$. Vitamin D insufficiency and deficiency during pregnancy have been linked to many pregnancy-related health complications and may also impair offspring health ${ }^{(11)}$. The most evident poor health outcome related to low vitamin D during fetal

Abbreviations: 25(OH)D, 25-hydroxyvitamin D; 25(OH)D 3 , 25-hydroxyvitamin $\mathrm{D}_{3}$; CV, cross-validation; DBS, dried blood spots; GC, group component; UVR, UV radiation.

* Corresponding author: A. Keller, email Amelie.Cleo.Keller@regionh.dk 
development and early life is the development of infancy and childhood rickets ${ }^{(12)}$. Apart from its role in $\mathrm{Ca}$ and phosphate homoeostasis and bone mineralisation ${ }^{(13)}$, vitamin $\mathrm{D}$ also has extra-skeletal functions such as regulation of hormone secretion, immune function and cellular proliferation and differentiation $^{(14,15)}$. Exposure to low vitamin D in utero may therefore predispose to a range of adverse health outcomes throughout life $^{(16)}$

The use of a proxy model may be of value when vitamin D measurements are lacking and thus need to be estimated. Environmental factors such as sunshine hours, temperature and UVR might explain seasonal fluctuations in vitamin D concentrations, but few studies have investigated the influence of these environmental factors during pregnancy on neonatal vitamin D concentrations. Most of these studies concerned season of birth in relation to cord blood measures of vitamin $\mathrm{D}^{(17,18)}$. In addition, some studies have used self-reported maternal intake of $25(\mathrm{OH}) \mathrm{D}$ or UVR exposure during pregnancy ${ }^{(19-21)}$ as well as season of birth as proxies of maternal or offspring $25(\mathrm{OH}) \mathrm{D}$ status in relation to the development of diseases in infancy and adulthood $^{(22-24)}$. However, currently there is poor understanding regarding the environmental factors or individual (maternal and offspring) characteristics that best contribute to determine neonatal 25(OH)D concentrations. Previous studies describing the determinants of neonatal $25(\mathrm{OH}) \mathrm{D}$ were based on either relative small samples $<300$ individuals or used cord blood 25(OH)D concentration $^{(21,25-30)}$. Only one previous study used $25(\mathrm{OH}) \mathrm{D}$ from dried blood spots (DBS) obtained from 259 children $^{(25)}$. Hence, there is a need for large cohort studies based on representative samples of the population using objective measurements of neonatal 25(OH)D. Furthermore, no previous studies have included measured bright sunshine hours and temperature as environmental proxies of $25(\mathrm{OH}) \mathrm{D}$ status among neonates. In Denmark, a relative low temperature might further prevent individuals from exposing their skin to the sun even when there is a high UV index and bright sunshine. Therefore, we hypothesised that UVR would be the main predictor of the neonatal 25hydroxyvitamin $\mathrm{D}_{3}\left(25(\mathrm{OH}) \mathrm{D}_{3}\right)$ variation and that temperature would be an additional important environmental determinant. We hypothesised that bright sunshine hours would be highly correlated to UVR and therefore be a minor additional environmental predictor. We also hypothesised that adding individual maternal and offspring characteristics would further improve the proxy model.

Therefore, using DBS from a large sample of Danish newborns, the aims of this study were to (1) identify environmental and individual determinants of $25(\mathrm{OH}) \mathrm{D}$ concentrations in newborns and (2) investigate whether these environmental factors and individual characteristics combined could be used as proxy measures for neonatal $25(\mathrm{OH}) \mathrm{D}$ concentrations.

\section{Methods}

$25(\mathrm{OH}) \mathrm{D}_{3}$ was measured from neonatal DBS from a random sub-sample of the Danish population of 2873 individuals, born between 1 May 1981 and 31 December 2002, retrieved from the Biological Specimen Bank for Neonatal Screening (BSBNS)-
Statens Serum Institute (SSI) in Denmark. Inclusion criteria were children born in Denmark, being alive 1 week after birth, and who had sufficient biological material from the DBS for the vitamin $\mathrm{D}$ analyses. Individuals were identified through the Danish Civil Registration system. No restriction on type of birth (multiple births) or gestational age was applied.

As part of a national routine screening programme for congenital disorders among neonates in Denmark, a heel prick is taken within 5-7 d after birth (until 2009 and within 48-72 h after birth thereafter). The blood samples were collected on filter paper and subsequently stored at $-20^{\circ} \mathrm{C}$ in a locked freezer at $\mathrm{SSI}^{(31)}$. To assess the $25(\mathrm{OH}) \mathrm{D}$ status, one $3.2 \mathrm{~mm}$ punch was taken halfway from the centre of the blood spot. A modified version of Eyles and colleagues' $\operatorname{method}^{(32)}$ of the highly sensitive liquid chromatography tandem MS method (LC-MS/MS) was used to measure the concentration of $25(\mathrm{OH}) \mathrm{D}$. It has previously been reported that $25(\mathrm{OH}) \mathrm{D}$ measurements from archived DBS are highly correlated with cord blood among neonates as well as with sera or plasma in adults ${ }^{(33,34)}$. Sample degradation occurring during 13-34 years storage time is unlikely, as studies have shown that, regardless of temperature and light exposure, storage times of $25(\mathrm{OH}) \mathrm{D}$ for up to 40 years do not bias inter-individual variation in concentrations for a given birth cohort ${ }^{(32,35)}$. Natural dietary sources of $25(\mathrm{OH}) \mathrm{D}_{2}$ are scarce and, in Denmark, vitamin D supplements come in the form of $25(\mathrm{OH}) \mathrm{D}_{3}$. Accordingly, more than $90 \%$ of $25(\mathrm{OH}) \mathrm{D}_{2}$ measured in the DBS were below the detection limit of $3 \mathrm{nmol} / 1$ and were therefore excluded from these analyses. All measured concentration levels for intra-assay and inter-assay analyses had acceptable precision, as the variability coefficient for intra-assay and inter-assay variation for $25(\mathrm{OH}) \mathrm{D}_{3}$ ranged $7-12$ and 7-20\%, respectively. There was no exclusion of the results based on the detection limit for $25(\mathrm{OH}) \mathrm{D}_{3}$, which was $4 \mathrm{nmol} / \mathrm{l}$. The concentration of $25(\mathrm{OH}) \mathrm{D}_{3}$ is reported in $\mathrm{nmol} / 1$ and the following formula, which takes into account the neonatal haematocrit fraction for capillary blood, was used to approximate the sera values: serum $\left(25(\mathrm{OH}) \mathrm{D}_{3}\right) \mathrm{nmol} / \mathrm{l}=\mathrm{DBS}$ $\left(25(\mathrm{OH}) \mathrm{D}_{3}\right) \mathrm{nmol} / \mathrm{l} \times 1 /(1-0.61$ (the Hct fraction $\left.)\right)^{(32,36)}$. The SSI laboratory participates in the vitamin D external quality assessment scheme with the equivalent-serum method ${ }^{(37)}$

Monthly aggregated data on daily number of bright sunshine hours recorded by Campbell-Stoke sunshine recorders ${ }^{(38)}$, average temperature recorded from thermometers placed $2 \mathrm{~m}$ above ground level in a ventilated screen or in a thermometer cabin $^{(39)}$, and UVR recorded from Brewer spectrophotometer ${ }^{(40)}$, available since 1993, were retrieved from the Danish Meteorological Institute ${ }^{(39)}$. The standard erythemal dose (SED, $\mathrm{J} / \mathrm{m}^{2}$ ) was used as the UVR unit. SED is a weighted measure of ambient UVR using an erythemal response function to give biologically effective UVR and is independent of skin tone ${ }^{(41)}$. Temperature was measured in ${ }^{\circ} \mathrm{C}$

Maternal characteristics age at delivery, education level, parity and smoking status during pregnancy; and offspring characteristics birth date, birth weight, gestational age at birth and sex were obtained from the Danish Medical Birth Register $(\mathrm{DMBR})^{(42)}$ via Statistics Denmark.

From 1991, binary (smokers or non-smokers) categorisation of maternal smoking status during pregnancy was started from 
manually collected data. Electronic data collection started in 1997 and further categories were added as follows: unknown, mother not smoking, mother smokes, mother stopped smoking in the first trimester, mother stopped smoking after the first trimester, mother smoked up to 5, 6-10, 11-20 or $>20$ cigarettes/d. Combining this information, maternal smoking was dichotomised into ever smoking (women who ever smoked during their pregnancy) $v$. never smoking (women who did not smoke during their pregnancy) or unknown. Ethnicity was defined based on the mother's place of birth and was dichotomised into European and non-European origin. Hence, children with fathers with nonEuropean origin were considered European if mothers were of European origin. Maternal education was categorised into school, high school and university as the highest education achievement level. Parity was dichotomised into primiparous and multiparous. Estimation of parity was based on summarised estimates of total births and the actual birth, as the DMBR only included information on live and still births before 1996. Maternal age at time of delivery was categorised as follows: <20, 20-24.9, 25-29.9, 30-34.9, 3539.9 and $>40$. Season of birth was defined based on the seasonal variation in serum $25(\mathrm{OH}) \mathrm{D}$ concentration among individuals from countries in northern latitudes ${ }^{(43,44)}$ : winter - born between November and January; spring - born between February and April; summer - born between May and July; autumn - born between August and October. Year of birth included 1993-2002. Gestational age at birth was based on gestational weeks (3744 weeks). Birth weight in grams was used and categorised as follows: $<2500,2500-4000$ and $>4000$.

\section{Ethics}

The Danish National Committee on Biomedical Research Ethics and Steering committee of the BSBNS granted permissions to access and analyse the DBS samples from the BSBNS (J. no. H-3-2011-126). Permission from the Danish Data Protection Agency was granted to merge biobank information with the other individual-level information from the Danish Administrative registers. (J. no. 2012-41-116).

\section{Statistical methods}

Forward selection of covariates based on the mean squared error (MSE) and subsequent cross-validation (CV) was used to determine the best predictive model based on the available data. Hence, each covariate was included by forward selection and at each selection step the covariate giving the highest reduction in the MSE of the previous model was included. The models resulting from the forward selection process were compared by estimating their out-of-sample performance using ten rounds of 5 -fold $\mathrm{CV}$ for each model, and the model with the lowest CV error was chosen as the final model ${ }^{(45)}$.

The base model was a linear mixed model, with partition of the residual variance into a between-group component (GC) and a within-GC, with individuals grouped by year of birth and in the month before the month of birth. UVR in the month before the month of birth was used in this study as the half-life of $25(\mathrm{OH}) \mathrm{D}$ during pregnancy is around $21 \mathrm{~d}^{(46)}$. To allow for a possible non-linear relationship between SED and $25(\mathrm{OH}) \mathrm{D}_{3}$, the forward selection algorithm had both a linear model and a restricted cubic spline model, with a single knot at the median value of UVR (210 SED) among the candidate models.

As $25(\mathrm{OH}) \mathrm{D}_{3}$ standard deviations increased proportionally with the mean (online Supplementary Fig. S1a and b), a generalised linear model with $\gamma$ distribution (where standard deviations are proportional to the mean) was used as sensitivity analysis.

We used $\mathrm{R}$ version $3.5 .0^{(47)}$. To generate the descriptive tables, we used the 'Hmisc' package ${ }^{(48)}$; and to fit the mixed models, we used the 'lme4' package ${ }^{(49)}$.

\section{Results}

UVR data were available from February 1993 only, therefore the sample was reduced from 2873 individuals to 1387 individuals born between February 1993 and December 2002. Individuals born preterm ( $<37$ gestational weeks) were further excluded as preterm births might be due to underlying causes that may influence maternal and fetal pregnancy outcomes and vitamin D concentrations ( $n$ 50) (Fig. 1). In addition, no seasonal pattern could be seen among neonates of non-European origin (defined according to maternal place of birth in the DMBR), therefore they were excluded from the analyses ( $n$ 139) (Fig. 1). After further exclusion of sixteen individuals with missing information on some of the covariates, a total of 1182 individuals were included in the analyses (Fig. 1). The mean $25(\mathrm{OH}) \mathrm{D}_{3}$ concentration was $30 \cdot 1$ (sD 19.8) nmol/1 and median 25.6 (range 0.5-110) nmol/1 when corrected for the haematocrit fraction. Maternal and offspring characteristics are presented in Table 1.

Vitamin D concentrations were higher among individuals born in summer and autumn and lower in winter and spring months $P<0.001$ (Fig. 2). Month of birth explained $24 \%$ of neonatal $25(\mathrm{OH}) \mathrm{D}_{3}$. The greatest correlation was between UVR and sunshine hours ( $r 0.93)$, followed by UVR and temperature $(r 0.86)$ and sunshine hours and temperature $(r 0 \cdot 80)$.

Assessment of the fitted spline (Fig. 3) showed that association between UVR and $25(\mathrm{OH}) \mathrm{D}_{3}$ was not linear and suggested a continuous increase in neonatal $25(\mathrm{OH}) \mathrm{D}_{3}$ with increased UVR.

Based on the available data and according to re-sampling method for model selection, the preferred model to predict $25(\mathrm{OH}) \mathrm{D}_{3}$ concentrations from neonatal DBS was the one including the group-level variables UVR (as a cubic spline) and temperature, together with the following individual-level variables: maternal education, maternal smoking during pregnancy, gestational age at birth and parity. This model explained $30 \%$ of the variation of $25(\mathrm{OH}) \mathrm{D}_{3}$ in the neonatal DBS with ambient UVR in the month before the month of birth, accounting for $24.5 \%$ of the neonatal $25(\mathrm{OH}) \mathrm{D}_{3}$ variance (Tables 2, 3 and Fig. 4).

The model was better at predicting between-group variation of neonatal $25(\mathrm{OH}) \mathrm{D}_{3}$ compared with within-group variation (grouped by year of birth and the month before the month of birth). Group-level determinants, UVR and temperature, explained more than $60 \%$ of the between group-level variation (standard deviation basal model: $10.6 \mathrm{nmol} / 1$ to standard deviation prediction model (model 6): $4.3 \mathrm{nmol} / \mathrm{l}$ ), while individual-level determinants (maternal education, maternal smoking during pregnancy, gestational age at birth and parity) explained $<0.5 \%$. 


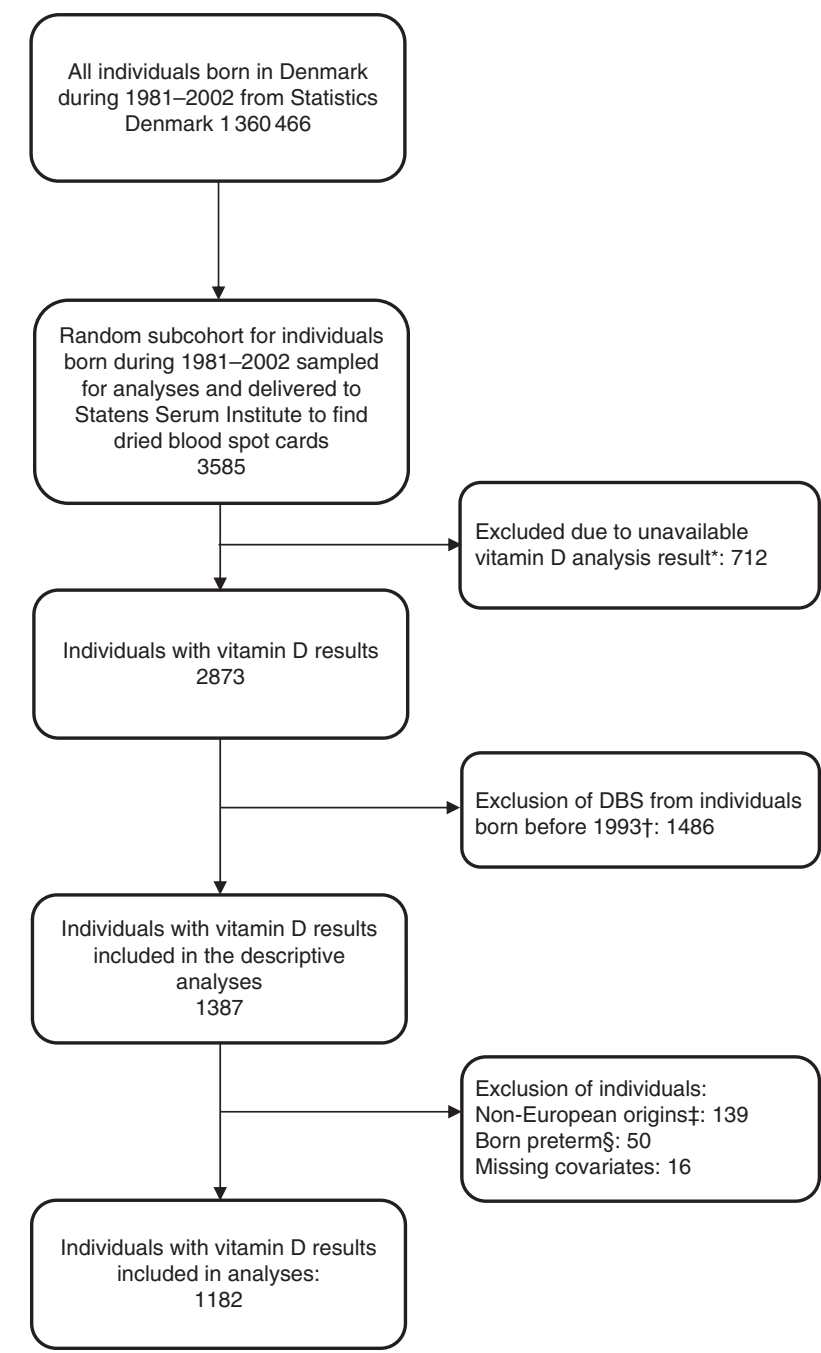

Fig. 1. Flow chart of study population. * Dried blood spot (DBS) cards were either not found, there was insufficient material for analysis or the analysis failed. † UV radiation data were available from February 1993 from the Danish Meteorological Institute. $¥$ No seasonal pattern could be seen among offspring of non-European individuals. $\S$ Individuals born preterm $(<37$ gestational weeks) were excluded as preterm births might be due to underlying causes that may influence maternal and fetal pregnancy outcomes and vitamin $D$ concentrations.

The within-group variation only reduced by $0.6 \%$ when both group-level and individual-level determinants were included in the model (standard deviation basal model: 16.5 to standard deviation prediction model (model 6): $15.9 \mathrm{nmol} / \mathrm{l}$ ) (Table 2). As $25(\mathrm{OH}) \mathrm{D}_{3}$ standard deviations increased proportionally with the mean (online Supplementary Fig. S1a and b), this suggests that our prediction model might be better at predicting $25(\mathrm{OH}) \mathrm{D}_{3}$ during winter and spring compared with summer and autumn. However, sensitivity analysis using generalised linear model with $\gamma$ distribution showed similar results (data not shown).

\section{Discussion}

This study examined the environmental and individual predictors of $25(\mathrm{OH}) \mathrm{D}$ concentrations measured from neonatal
DBS among a representative sample of neonates born in Denmark. Our findings showed as expected a seasonal pattern of vitamin D concentration, with higher values in summer and autumn and lower values in winter and spring. Ambient UVR in the month before the month of birth was the best predictor of neonatal $25(\mathrm{OH}) \mathrm{D}_{3}$, accounting for $24 \%$ of its variance. Neonatal $25(\mathrm{OH}) \mathrm{D}_{3}$ concentration was further determined by other factors such as ambient temperature, maternal education, maternal smoking during pregnancy, gestational age at birth and parity. The final model explained $30 \%$ of neonatal $25(\mathrm{OH}) \mathrm{D}_{3}$ concentration from DBS. The model best predicted between-group (grouped by year of birth and in the month before the month of birth) variation of neonatal $25(\mathrm{OH}) \mathrm{D}_{3}$ compared with within-group variation, and individual-level determinants explained only a small proportion of the between group-level variation. Our findings might be explained by the natural yearly and monthly variation in ambient UVR and temperature. Furthermore, our findings suggest that the individual-level determinants included in the model might only have a marginal influence on neonatal $25(\mathrm{OH}) \mathrm{D}_{3}$ concentration. Our findings suggest that less than a third of neonatal $25(\mathrm{OH}) \mathrm{D}_{3}$ concentration could be predicted by our model. Hence, this model might prove useful in cohort studies assessing the association between neonatal vitamin $\mathrm{D}$ and disease outcomes for ranking individuals in groups according to $25(\mathrm{OH}) \mathrm{D}_{3}$ status. However, it cannot substitute actual blood measurements as a tool for evaluating individual vitamin $\mathrm{D}$ status, as only a proportion of the variation in $25(\mathrm{OH}) \mathrm{D}_{3}$ could be appraised ${ }^{(20)}$.

Previous prediction models of maternal or neonatal $25(\mathrm{OH}) \mathrm{D}$ concentrations found higher prediction than ours, explaining between $40^{(20)}$ and $43 \%{ }^{(25)}$ of the total $25(\mathrm{OH}) \mathrm{D}$ variance. This difference might relate to the different variables included in the prediction models, distinct study population characteristics, differences in sample sizes and potentially different analytical methods used.

The strengths of the present study include the large sample of individuals randomly selected among the entire Danish population and measurements of neonatal biological $25(\mathrm{OH}) \mathrm{D}_{3}$ from DBS as well as the use of the high-quality register data from the DMBR. The use of the resampling method with MSE and $\mathrm{CV}$ guaranteed, to some degree, that the best model could be selected preventing overfitting. Furthermore, $25(\mathrm{OH}) \mathrm{D}_{3}$ concentrations were measured using the validated modified version of Eyles and colleagues' method ${ }^{(32)}$ of the highly sensitive LC-MS/MS.

The study also has limitations. Data on sunshine hours, temperature and UVR in the month before the month of birth obtained from the DMI were group-level determinants aggregated monthly; therefore, within-month variation including inter- and intra-individual exposure variations could not be assessed. Furthermore, pure UVB measurements, which are responsible for vitamin D skin synthesis, were only available from 2015. Therefore, it was only possible to include UVR in our model. However, as UVR measurements correlate very closely to vitamin D synthesis, it is not expected that the use of UVB instead of UVR would have greatly influenced our predictive model ${ }^{(50)}$.

It has been reported that breastfed infants are at an increased risk of vitamin D deficiency compared with formula-fed infants $^{(51)}$. As DBS were collected within $7 \mathrm{~d}$ after birth, the 
Table 1. Maternal and offspring characteristics

\begin{tabular}{|c|c|c|c|c|c|}
\hline Variables & & $(n$ 1232) & Mean $25(\mathrm{OH}) \mathrm{D}_{3}(\mathrm{nmol} / \mathrm{l})$ & SD & $P$ \\
\hline \multirow[t]{2}{*}{ Offspring sex } & Male & 611 & $30 \cdot 6$ & $20 \cdot 0$ & 0.33 \\
\hline & Female & 571 & 29.5 & $20 \cdot 0$ & \\
\hline \multirow[t]{12}{*}{ Offspring month of birth } & January & 85 & 21.9 & $12 \cdot 4$ & $<0.001$ \\
\hline & February & 100 & $20 \cdot 6$ & $15 \cdot 6$ & \\
\hline & March & 102 & $21 \cdot 0$ & $15 \cdot 1$ & \\
\hline & April & 93 & 18.6 & 13.5 & \\
\hline & May & 116 & $28 \cdot 3$ & $16 \cdot 6$ & \\
\hline & June & 96 & 37.6 & $18 \cdot 1$ & \\
\hline & July & 115 & $46 \cdot 7$ & $23 \cdot 1$ & \\
\hline & August & 111 & 44.9 & $19 \cdot 4$ & \\
\hline & September & 102 & $36 \cdot 9$ & $19 \cdot 4$ & \\
\hline & October & 84 & $28 \cdot 8$ & $17 \cdot 4$ & \\
\hline & November & 104 & 24.3 & $15 \cdot 3$ & \\
\hline & December & 74 & 23.8 & $18 \cdot 0$ & \\
\hline \multirow[t]{10}{*}{ Offspring year of birth } & 1993 & 97 & $30 \cdot 2$ & $20 \cdot 9$ & $<0.001$ \\
\hline & 1994 & 146 & 30.7 & $20 \cdot 3$ & \\
\hline & 1995 & 136 & $34 \cdot 2$ & $19 \cdot 8$ & \\
\hline & 1996 & 119 & 26.5 & $16 \cdot 3$ & \\
\hline & 1997 & 124 & $25 \cdot 6$ & $17 \cdot 8$ & \\
\hline & 1998 & 116 & $22 \cdot 9$ & $13 \cdot 3$ & \\
\hline & 1999 & 124 & 30.0 & $19 \cdot 3$ & \\
\hline & 2000 & 111 & $32 \cdot 2$ & $19 \cdot 0$ & \\
\hline & 2001 & 119 & 36.5 & $24 \cdot 1$ & \\
\hline & 2002 & 90 & 31.8 & $22 \cdot 3$ & \\
\hline \multirow[t]{3}{*}{ Offspring birth weight (g) } & $<2500$ & 19 & $32 \cdot 9$ & $23 \cdot 4$ & 0.78 \\
\hline & 2500-3999 & 889 & 29.9 & $19 \cdot 8$ & \\
\hline & $>4000$ & 274 & $30 \cdot 5$ & $19 \cdot 5$ & \\
\hline \multirow{7}{*}{$\begin{array}{l}\text { Offspring gestational age } \\
\text { at birth (weeks) }\end{array}$} & 37 & 23 & 35.5 & $25 \cdot 4$ & 0.08 \\
\hline & 38 & 85 & $28 \cdot 2$ & $16 \cdot 0$ & \\
\hline & 39 & 202 & $31 \cdot 1$ & $20 \cdot 3$ & \\
\hline & 40 & 310 & 31.9 & 20.5 & \\
\hline & 41 & 305 & $30 \cdot 1$ & $20 \cdot 6$ & \\
\hline & 42 & 187 & $27 \cdot 0$ & $17 \cdot 4$ & \\
\hline & $43>$ & 70 & $27 \cdot 3$ & 18.5 & \\
\hline \multirow{4}{*}{$\begin{array}{l}\text { Maternal age at time of } \\
\text { delivery (years) }\end{array}$} & $<25$ & 170 & $24 \cdot 6$ & $18 \cdot 0$ & $<0.001$ \\
\hline & $25-29 \cdot 9$ & 450 & 31.4 & $20 \cdot 2$ & \\
\hline & $30-34.9$ & 393 & $32 \cdot 0$ & 20.5 & \\
\hline & $>35$ & 169 & $27 \cdot 7$ & $17 \cdot 3$ & \\
\hline \multirow[t]{4}{*}{ Maternal education } & School & 248 & $24 \cdot 7$ & $17 \cdot 9$ & $<0.001$ \\
\hline & High school & 610 & 31.0 & $20 \cdot 0$ & \\
\hline & University & 308 & $32 \cdot 3$ & 19.9 & \\
\hline & Unknown & 16 & 31.9 & $22 \cdot 7$ & \\
\hline \multirow{3}{*}{$\begin{array}{l}\text { Maternal smoking during } \\
\text { pregnancy }\end{array}$} & Yes & 272 & $25 \cdot 1$ & $18 \cdot 2$ & $<0.001$ \\
\hline & No & 858 & 31.8 & $20 \cdot 1$ & \\
\hline & Unknown & 52 & $27 \cdot 6$ & 18.5 & \\
\hline \multirow[t]{2}{*}{ Parity } & Primiparous & 507 & $31 \cdot 7$ & $19 \cdot 8$ & 0.01 \\
\hline & Multiparous & 675 & 28.8 & 19.7 & \\
\hline
\end{tabular}

$25(\mathrm{OH}) \mathrm{D}_{3}, 25$-hydroxyvitamin $\mathrm{D}_{3}$

concentration of $25(\mathrm{OH}) \mathrm{D}_{3}$ between breastfed and formula-fed infants could differ. In the present study, data about breast-feeding were not available; however, in Denmark $<5 \%$ of infants are not being breastfed at the time of hospital discharge ${ }^{(52)}$. Therefore, as our sample is representative of the Danish population, we expect similar rates in our cohort. Furthermore, supplementation with vitamin $\mathrm{D}$ is first recommended from 2 weeks of age ${ }^{(53)}$; therefore, $25(\mathrm{OH}) \mathrm{D}$ concentration from neonatal DBS is not expected to be affected by supplementation.

Vitamin D dietary intake from supplements and dairy products has previously been identified as a determinant of vitamin $\mathrm{D}$ status in pregnant women and neonates ${ }^{(28)}$; therefore, including these variables in the model would potentially have added to the explanation of a bigger proportion of the neonatal $25(\mathrm{OH}) \mathrm{D}$ variation. Furthermore, maternal body weight has been identified as a determinant of vitamin D status in pregnant women and neonates in some $e^{(28)}$ but not all studies ${ }^{(20)}$ (pregnant women only). Therefore, it is unclear whether including this variable would have influenced our prediction model.

The influence on the prediction of factors such as outdoor activity, tanning beds use, sun exposure habits, skin colour, use of sunscreen and clothing habits known to influence maternal vitamin D skin synthesis could not be assessed in this study as such data were not available. Results from two studies from the UK have suggested that fair-skinned individuals need 9 min of daily sunlight at lunchtime from March to September, for $25(\mathrm{OH}) \mathrm{D}$ concentrations to remain $>25 \mathrm{nmol} / 1$ throughout the winter and without causing erythema (sun burnt), while dark-skinned individuals need approximately $25 \mathrm{~min}^{(54,55)}$. In the study by Smith 
et $a l .{ }^{(25)}$, maternal clothing and sun exposure habits explained $4 \%$ of neonatal $25(\mathrm{OH}) \mathrm{D}$ variance; and in another study, the use of sunscreen and skin pigmentation were described as possible determinants of maternal 25(OH)D deficiency (defined as

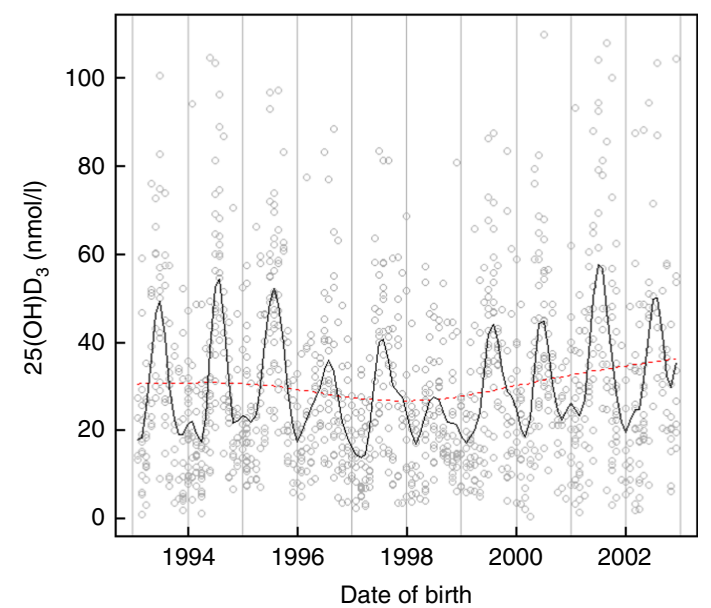

Fig. 2. Neonatal 25-hydroxyvitamin $D_{3}\left(25(\mathrm{OH}) \mathrm{D}_{3}\right)$ variations by month and year of birth among a random sample of infants born between 1993 and 2002 in Denmark.

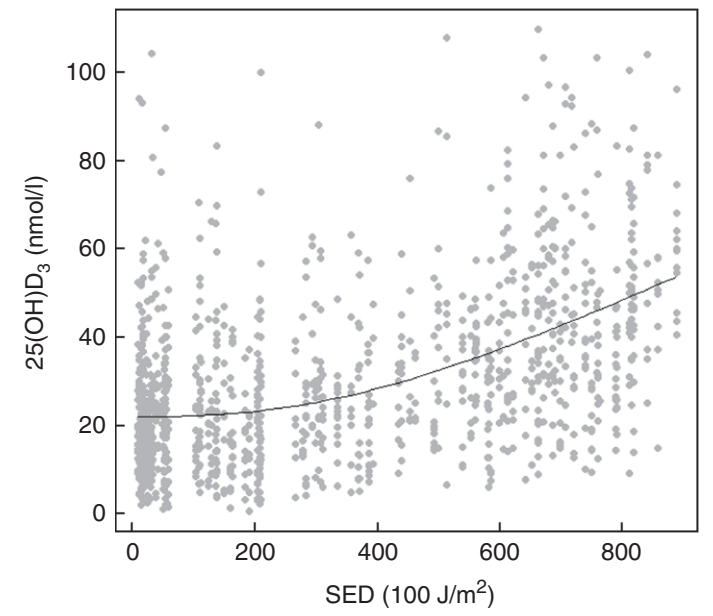

Fig. 3. UV radiation (standard erythemal dose (SED, $\left.\mathrm{J} / \mathrm{m}^{2}\right)$ ) and neonatal 25-hydroxyvitamin $\mathrm{D}_{3}\left(25(\mathrm{OH}) \mathrm{D}_{3}\right)$ among a random sample of infants born between 1993 and 2002 in Denmark.
$<50 \mathrm{nmol} / \mathrm{l})^{(21)}$. Therefore, these variables may be expected to explain a small proportion of neonatal $25(\mathrm{OH}) \mathrm{D}_{3}$ concentration and inclusion in our prediction model would have strengthened our model.

A recent genome-wide association study meta-analysis of serum $25(\mathrm{OH}) \mathrm{D}$ among European individuals validated three $25(\mathrm{OH}) \mathrm{D}$ risk loci (GC, 7-dehydrocholesterol reductase (NADSYN1/DHCR7) and CYP2R1) previously identified, and identified two new loci (Sec23 homolog A, coat protein complex II component and amidohydrolase domain containing 1 ). The study reported that there was a modest overall heritability in serum $25(\mathrm{OH}) \mathrm{D}$ among European individuals due to the common genome-wide SNP of $7 \cdot 5 \%{ }^{(56)}$. In the Danish population, the $25(\mathrm{OH}) \mathrm{D}$ risk loci in GC and 25-hydroxylase (CYP2R1) were associated with serum 25(OH) D concentrations ${ }^{(57)}$; and in Hungary, selected SNP (NADSYN1, DHCR7, GC, CYP2R1 and CYP24A1) accounted for $13 \cdot 1 \%$ of the

Table 3. Multivariable model of factors predicting 25-hydroxyvitamin $D_{3}$ $\left(25(\mathrm{OH}) \mathrm{D}_{3}\right)(\mathrm{nmol} / \mathrm{l})$ concentration from neonatal dried blood spots

\begin{tabular}{|c|c|c|}
\hline \multicolumn{2}{|l|}{ Variables } & \multirow{2}{*}{$\frac{\text { Estimate }}{25.3}$} \\
\hline Intercept & & \\
\hline \multirow[t]{3}{*}{ Maternal smoking during pregnancy } & No & Ref. \\
\hline & Yes & $-4 \cdot 7$ \\
\hline & Unknown & -3.5 \\
\hline \multirow[t]{4}{*}{ Maternal education } & School & Ref. \\
\hline & High school & $5 \cdot 6$ \\
\hline & University & $7 \cdot 2$ \\
\hline & Unknown & $4 \cdot 8$ \\
\hline \multirow[t]{2}{*}{ Parity } & Primiparous & Ref. \\
\hline & Multiparous & -2.9 \\
\hline \multirow[t]{7}{*}{ Gestational age at birth (weeks) } & 37 & Ref. \\
\hline & 38 & -4.9 \\
\hline & 39 & $-4 \cdot 2$ \\
\hline & 40 & -3.5 \\
\hline & 41 & $-4 \cdot 7$ \\
\hline & 42 & $-7 \cdot 3$ \\
\hline & $43>$ & $-8 \cdot 8$ \\
\hline Temperature residuals $\left({ }^{\circ} \mathrm{C}\right)$ & Continuous & $2 \cdot 1^{*}$ \\
\hline UVR spline term 1 (SED) & Continuous & $17 \cdot 1 \dagger$ \\
\hline UVR spline term 2 (SED) & Continuous & $32 \cdot 7 \dagger$ \\
\hline \multicolumn{3}{|c|}{$\begin{array}{l}\text { Ref., referent values; UVR, UV radiation; SED, standard erythemal dose. } \\
\text { * Standardised to mean zero and standard deviation one: one standard deviation = } \\
3.1^{\circ} \mathrm{C} \text {. } \\
\text { †The spline basis was bases on SED values standardised to mean zero and } \\
\text { standard deviation one. One standard deviation }=291.4 \text { SED. }\end{array}$} \\
\hline
\end{tabular}

Table 2. Prediction model selection*

\begin{tabular}{|c|c|c|c|c|c|c|}
\hline Model & df & MSE & CV error & Between-group SD & Within-group SD & $R^{2}(\%)$ \\
\hline Base & 1179 & $390 \cdot 7$ & 391.4 & $10 \cdot 6$ & $16 \cdot 5$ & 0 \\
\hline 1 & 1177 & 294.8 & 296.8 & 4.7 & $16 \cdot 5$ & 24.5 \\
\hline 2 & 1174 & 285.7 & $289 \cdot 4$ & 4.7 & $16 \cdot 2$ & $26 \cdot 8$ \\
\hline 3 & 1173 & $281 \cdot 3$ & $285 \cdot 3$ & 4.2 & $16 \cdot 2$ & 27.9 \\
\hline 4 & 1171 & $277 \cdot 9$ & 282.4 & 4.4 & $16 \cdot 1$ & 28.8 \\
\hline 5 & 1165 & 274.9 & 283.2 & 4.3 & $16 \cdot 0$ & $29 \cdot 6$ \\
\hline 6 & 1164 & 273.0 & 281.2 & 4.3 & $15 \cdot 9$ & $30 \cdot 1$ \\
\hline 7 & 1161 & $270 \cdot 6$ & $282 \cdot 1$ & $4 \cdot 2$ & $15 \cdot 9$ & 30.7 \\
\hline 8 & 1159 & $270 \cdot 3$ & $283 \cdot 2$ & 4.3 & $15 \cdot 9$ & $30 \cdot 8$ \\
\hline 9 & 1158 & $270 \cdot 0$ & $283 \cdot 1$ & 4.2 & $15 \cdot 9$ & 30.8 \\
\hline
\end{tabular}

MSE, mean square error; $C V$, cross-validation; $R^{2}$, explained variation without conditioning on group level parameters.

* Base model by year of birth and in the month before the month of birth; model 1: model 0+ UVR; model 2: model 1 + education; model 3: model $2+$ temperature; model 4: model 3 + maternal smoking during pregnancy; model 5 : model $4+$ gestational age at birth; model 6 : model $5+$ parity; model 7: model 6+ maternal age at delivery; model 8: model 7 + birth weight; model 9: model $8+$ sex. 


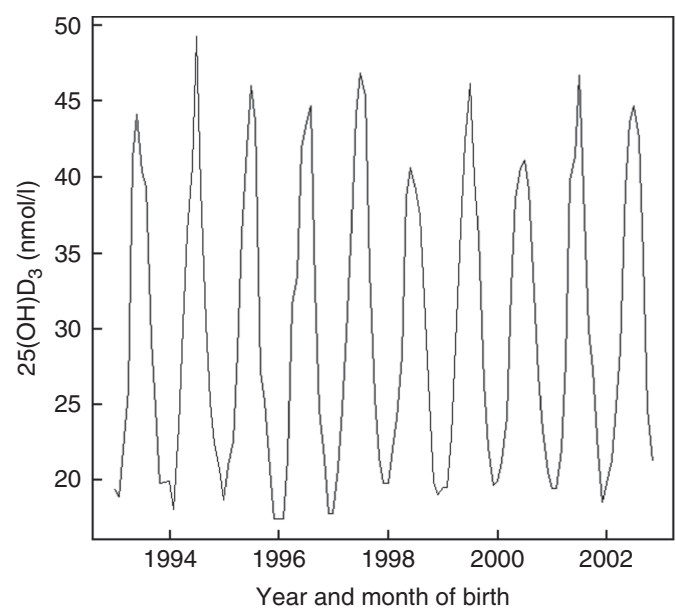

Fig. 4. Prediction of neonatal 25-hydroxyvitamin $D_{3}\left(25(\mathrm{OH}) \mathrm{D}_{3}\right)$ from the multilevel analysis based on a random sample of infants born between 1993 and 2002 in Denmark.

variance of total $25(\mathrm{OH}) \mathrm{D}$ levels ${ }^{(58)}$. In Australia, the study by Smith et al. ${ }^{(25)}$ reported that $5.2 \%$ of the predicted variance in neonatal 25(OH)D from DBS could be explained by infant genetic variants GC (rs2282679) and DHCR7 (rs12785878). Therefore, including information on genetic variance would also have most likely improved our model.

Information about maternal smoking status was missing for more than $40 \%$ of individuals and reporting bias may have occurred. Therefore, the true effect of smoking on neonatal 25(OH)D concentration might have been underestimated. However, results from different studies suggest a non-significant inverse association between maternal smoking and maternal and neonatal $25(\mathrm{OH}) \mathrm{D}$ concentrations ${ }^{(21,28,59)}$. Therefore, maternal smoking during pregnancy might only marginally predict offspring $25(\mathrm{OH}) \mathrm{D}$ concentration at birth.

A high correlation $(r \geq 0.83)$ between maternal and neonatal vitamin D concentrations has been previously reported, with maternal vitamin D concentration explaining between 69 and $77 \%$ of the neonatal one ${ }^{(3,60)}$. Maternal $25(\mathrm{OH}) \mathrm{D}$ was not available in this study. However, the environmental factors and individual characteristics (UVR, temperature, parity, gestational age at birth, maternal education and maternal smoking during pregnancy) included in this study can be thought of as both maternal and offspring's proxies of $25(\mathrm{OH}) \mathrm{D}$ concentrations. As our model explained $30 \%$ of neonatal $25(\mathrm{OH}) \mathrm{D}_{3}$ concentration, determinants other than the ones included in our model must play a significant role in both maternal and neonatal $25(\mathrm{OH}) \mathrm{D}_{3}$ concentrations.

Finally, the present results might only be generalised to populations living at high latitudes $\left(56^{\circ}\right.$ North) and with fair skin.

\section{Conclusion}

Ambient UVR in the month before the month of birth was the best predictor of neonatal $25(\mathrm{OH}) \mathrm{D}_{3}$, accounting for $24 \%$ of its variance. Neonatal $25(\mathrm{OH}) \mathrm{D}_{3}$ concentration was further determined by maternal and offspring characteristics, but the final model explained an additional $6 \%$ of neonatal $25(\mathrm{OH}) \mathrm{D}_{3}$ only, leaving $70 \%$ of the variation to be explained by other genetic and environmental factors and individual characteristics. Hence, although this model cannot substitute actual blood measurements, it might prove useful in cohort studies for ranking individuals in groups according to $25(\mathrm{OH}) \mathrm{D}_{3}$ status.

\section{Acknowledgements}

The authors would like to thank Paul Eriksen from the Danish Meteorological Institute for his help in providing relevant documents regarding UVR measurement methods used in Denmark.

The study is a part of the 4-year project 'D-tect' funded by the Programme Commission on Health, Food and Welfare under the Danish Council for Strategic research (grant number 060300453B). The Danish Diabetes Academy supported by the Novo Nordisk Foundation. The Lundbeck Foundation (grant number R170-2014-643). The funders had no role in study design, data collection and analysis, decision to publish or preparation of the manuscript.

B. L. H., P. F., R. J. and A. K. designed the study and formulated the research question. P. F. performed the statistical analyses. R. J. and M. N. H. provided feedback on the study design. A. K. wrote the manuscript. J. M. and A. S. C. provided interpretation of data and critical revision of the manuscript for important intellectual content.

None of the authors had any conflicts of interest.

\section{Supplementary material}

For supplementary material/s referred to in this article, please visit https://doi.org/10.1017/S0007114518003604

\section{References}

1. Bodnar LM, Simhan HN, Powers RW, et al. (2007) High prevalence of vitamin $\mathrm{D}$ insufficiency in black and white pregnant women residing in the northern United States and their neonates 1. J Nutr 137, 447-452.

2. Mcaree T, Jacobs B, Manickavasagar T, et al. (2013) Original article vitamin $\mathrm{D}$ deficiency in pregnancy - still a public health issue. Matern Child Nutr 9, 23-30.

3. Streym S, Moller UK, Rejnmark L, et al. (2013) Maternal and infant vitamin D status during the first 9 months of infant life a cohort study. Eur J Clin Nutr 67, 1022-1028.

4. Andersen R, Brot C, Jakobsen J, et al. (2013) Seasonal changes in vitamin D status among Danish adolescent girls and elderly women: the influence of sun exposure and vitamin $\mathrm{D}$ intake. Eur J Clin Nutr 67, 270-274.

5. Spiro A \& Buttriss JL (2014) Vitamin D: an overview of vitamin D status and intake in Europe. Nutr Bull 39, 322-350.

6. Prentice A (2008) Vitamin D deficiency: a global perspective. Nutr Rev 66, 153-164.

7. Holick MF (2007) Vitamin D deficiency. N Engl J Med 357, 266-281.

8. Milman N, Hvas A \& Bergholt T (2012) Vitamin D status during normal pregnancy and postpartum. A longitudinal study in 141 Danish women. J Perinat Med 40, 57-61.

9. Andersen LB, Abrahamsen B, Dalg C, et al. (2013) Parity and tanned white skin as novel predictors of vitamin D status in early pregnancy: a population-based cohort study. Clin Endocrinol (Oxf) 79, 333-341. 
10. Petersen SB, Olsen SF, Mølgaard C, et al. (2014) Maternal vitamin $\mathrm{D}$ status and offspring bone fractures: prospective study over two decades in Aarhus City, Denmark. PLOS ONE 9, e114334.

11. Karras SN, Fakhoury H, Muscogiuri G, et al. (2016) Maternal vitamin D levels during pregnancy and neonatal health: evidence to date and clinical implications. Ther Adv Musculoskelet Dis $\mathbf{8}$, 124-135.

12. Sahay M \& Sahay R (2012) Rickets - vitamin D deficiency and dependency. Indian J Endocrinol Metab 16, 164-176.

13. Norman AW (2008) From vitamin D to hormone D: fundamentals of the vitamin $\mathrm{D}$ endocrine system essential for good health. Am J Clin Nutr 88, 491S-499S.

14. Yang L, Ma J, Zhang X, et al. (2012) Protective role of the vitamin D receptor. Cell Immunol 279, 160-166.

15. Bikle D (2009) Nonclassic actions of vitamin D. J Clin Endocrinol Metab 94, 26-34.

16. Hyppönen E, Läärä E, Reunanen A, et al. (2001) Intake of vitamin $\mathrm{D}$ and risk of type 1 diabetes: a birth-cohort study. Lancet (London, England) 358, 1500-1503.

17. Vinkhuyzen AAE, Eyles DW, Burne TH, et al. (2016) Prevalence and predictors of vitamin D deficiency based on maternal midgestation and neonatal cord bloods: the Generation R Study. J Steroid Biochem Mol Biol 164, 161-167.

18. Basile LA, Taylor SN, Wagner CL, et al. (2007) Neonatal vitamin D status at birth at latitude 32 degrees 72': evidence of deficiency. J Perinatol 27, 568-571.

19. Petersen SB, Strøm M, Maslova E, et al. (2015) Predicted vitamin $\mathrm{D}$ status during pregnancy in relation to offspring forearm fractures in childhood: a study from the Danish National Birth Cohort. Br J Nutr 114, 1900-1908.

20. Bjørn Jensen C, Thorne-Lyman AL, Vadgård Hansen L, et al. (2013) Development and validation of a vitamin D status prediction model in Danish pregnant women: a study of the Danish National Birth Cohort. PLOS ONE 8, e53059.

21. Krieger J-P, Cabaset S, Canonica C, et al. (2018) Prevalence and determinants of vitamin D deficiency in the third trimester of pregnancy: a multicentre study in Switzerland. Br J Nutr 119, 299-309.

22. Jensen CB, Zimmermann E, Gamborg M, et al. (2015) No evidence of seasonality of birth in adult type 2 diabetes in Denmark. Diabetologia 58, 2045-2050.

23. Svensson J, Lyngaae-Jørgensen A, Carstensen B, et al. (2009) Long-term trends in the incidence of type 1 diabetes in Denmark: the seasonal variation changes over time. Pediatr Diabetes 10, 248-254.

24. Vassallo MF, Banerji A, Rudders SA, et al. (2010) Season of birth and food allergy in children. Ann Allergy Asthma Immunol 104, 307-313.

25. Smith CA, Sun C, Pezic A, et al. (2017) Determinants of neonatal vitamin $\mathrm{D}$ levels as measured on neonatal dried blood spot samples. Neonatology 111, 153-161.

26. Novakovic B, Galati JC, Chen A, et al. (2012) Maternal vitamin D predominates over genetic factors in determining neonatal circulating vitamin D concentrations. Am J Clin Nutr 96, $188-195$.

27. Karras SN, Shah I, Petroczi A, et al. (2013) An observational study reveals that neonatal vitamin $\mathrm{D}$ is primarily determined by maternal contributions: implications of a new assay on the roles of vitamin D forms. Nutr J 12, 77.

28. Woolcott CG, Giguère Y, Weiler HA, et al. (2016) Determinants of vitamin $\mathrm{D}$ status in pregnant women and neonates. Can J Public Heal 107, e410-e416.

29. Yu X, Wang W, Wei Z, et al. (2014) Vitamin D status and related factors in newborns in Shanghai, China. Nutrients $\mathbf{6}$, $5600-5610$.
30. Kelishadi R, Sharifi-Ghazvini F, Poursafa P, et al. (2013) Determinants of hypovitaminosis D in pregnant women and their newborns in a sunny region. Int J Endocrinol 2013, 460970.

31. Nørgaard-Pedersen B \& Hougaard DM (2007) Storage policies and use of the Danish newborn screening biobank. J Inherit Metab Dis 30, 530-536.

32. Eyles D, Anderson C, Ko P, et al. (2009) A sensitive LC/MS/MS assay of $25 \mathrm{OH}$ vitamin $\mathrm{D}_{3}$ and $25 \mathrm{OH}$ vitamin $\mathrm{D}_{2}$ in dried blood spots. Clin Chim Acta 403, 145-151.

33. Eyles DW, Morley R, Anderson C, et al. (2010) The utility of neonatal dried blood spots for the assessment of neonatal vitamin D status. Paediatr Perinat Epidemiol 24, 303-308.

34. Heath AK, Williamson EJ, Ebeling PR, et al. (2015) Measurements of 25-hydroxyvitamin D concentrations in archived dried blood spots are reliable and accurately reflect those in plasma. J Clin Endocrinol Metab 99, 3319-3324.

35. Bodnar LM, Catov JM, Wisner KL, et al. (2009) Racial and seasonal differences in 25-hydroxyvitamin $\mathrm{D}$ detected in maternal sera frozen for over 40 years. Br J Nutr 101, 278-284.

36. Kayiran SM, Ozbek N, Turan M, et al. (2003) Significant differences between capillary and venous complete blood counts in the neonatal period. Clin Lab Haematol 25, 9-16.

37. Carter GD, Berry J, Durazo-Arvizu R, et al. (2018) Hydroxyvitamin D assays: an historical perspective from DEQAS. J Steroid Biochem Mol Biol 177, 30-35.

38. Laursen EV \& Cappelsen J (1998) Observed hours of bright sunshine in Denmark - with climatological standard normals, 1961-90. DMI Technical Report 98-4.

39. Cappelen J, Kern-Hansen C, Laursen EV, et al. (2012) Denmark - DMI historical climate data collection 1768-2011. Technical Report 12-02.

40. Eriksen P, Jepsen N, Jønch-Sørensen H, et al. (2015) Ozonlaget over Danmark og Grønland 1979-2014 (Ozone layer over Denmark and Greenland 1979-2013). Danmarks Klimacenter rapport 14-03.

41. Lucas R \& Prüss-Üstün A, World Health Organization (2006) Solar Ultraviolet Radiation: Global Burden of Disease from Solar Ultraviolet Radiation. Geneva: WHO.

42. Bliddal M, Broe A, Pottegård A, et al. (2018) The Danish medical birth register. Eur J Epidemiol 33, 27-36.

43. Godang K, Froslie KF, Henriksen T, et al. (2014) Seasonal variation in maternal and umbilical cord $25(\mathrm{OH})$ vitamin $\mathrm{D}$ and their associations with neonatal adiposity. Eur J Endocrinol 170, 609-617.

44. Hyppönen E \& Power C (2007) Hypovitaminosis D in British adults at age $45 \mathrm{y}$ : nationwide cohort study of dietary and lifestyle predictors. Am J Clin Nutr 85, 860-868.

45. James G, Witten D, Hastie T, et al. (2013) An Introduction to Statistical Learning Statistics An Introduction to Statistical Learning with Applications in R. New York: Springer.

46. Jones KS, Assar S, Prentice A, et al. (2016) Vitamin D expenditure is not altered in pregnancy and lactation despite changes in vitamin D metabolite concentrations. Sci Rep 6, 26795.

47. The R Foundation (2018) R: The R Project for Statistical Computing. https://www.r-project.org/ (accessed July 2018).

48. Harrell FE Jr (2018) CRAN - Package Hmisc. https://cran.r-project.org/web/packages/Hmisc/index.html (accessed July 2018).

49. Bates D, Mächler M, Bolker B, et al. (2015) Fitting linear mixed-effects models using lme4. J Stat Softw 67, 1-48.

50. Eriksen P (2015) UV stråling og UV-indeks (UV radiation and UV index).

51. Gordon CM, Feldman HA, Sinclair L, et al. (2008) Prevalence of vitamin D deficiency among healthy infants and toddlers. Arch Pediatr Adolesc Med 162, 505-512.

52. Fenger-Grøn J, Fenger-Grøn M, Blunck CH, et al. (2015) Low breastfeeding rates and body mass index in Danish 
children of women with gestational diabetes mellitus. Int Breastfeed J 10, 26.

53. Klahn IR (2013) Fra "Ro, Renlighed og Regelmoessighed" til "Barnets naturlige rytme" (From "Peace, Cleanliness and Regularity" to "The child's natural rhythm"). University of Copenhagen.

54. Webb A, Kazantzidis A, Kift R, et al. (2018) Colour counts: sunlight and skin type as drivers of vitamin D deficiency at UK Latitudes. Nutrients 10, 457.

55. Webb A, Kazantzidis A, Kift R, et al. (2018) Meeting vitamin D requirements in white Caucasians at UK latitudes: providing a choice. Nutrients 10, 497.

56. Jiang X, O'Reilly PF, Aschard H, et al. (2018) Genome-wide association study in 79,366 European-ancestry individuals informs the genetic architecture of 25-hydroxyvitamin D levels. Nat Commun 9, 260.
57. Nissen J, Rasmussen LB, Ravn-Haren G, et al. (2014) Common variants in CYP2R1 and GC genes predict vitamin D concentrations in healthy Danish children and adults. PLOS ONE 9, e89907.

58. Szili B, Szabó B, Horváth $\mathrm{P}$, et al. (2018) Impact of genetic influence on serum total- and free 25-hydroxyvitamin-D in humans. J Steroid Biochem Mol Biol 183, 62-67.

59. Banihosseini SZ, Baheiraei A, Shirzad N, et al. (2013) The effect of cigarette smoke exposure on vitamin D level and biochemical parameters of mothers and neonates. J Diabetes Metab Disord 12, 19.

60. Rodda CP, Benson JE, Vincent AJ, et al. (2015) Maternal vitamin D supplementation during pregnancy prevents vitamin $\mathrm{D}$ deficiency in the newborn: an open-label randomized controlled trial. Clin Endocrinol (Oxf) 83, 363-368. 